\title{
Colonic Mucosal Infiltration of IgG4 Plasma Cells and Ulcerative Colitis: Determinant of Presence, Activity, Extension, and Duration of Disease
}

Foroogh Alborzi ${ }^{1}$,Nasser Ebrahimi Daryani ${ }^{2}$,Tina Deihim ${ }^{3}$, Zahra Azizi ${ }^{4}$,Farid Azmoudeh Ardalan ${ }^{5}$, Azam Teimouri ${ }^{6}$, Reza Taslimi ${ }^{1}$, Nader Roshan ${ }^{7}$, Masood Mami ${ }^{8}$, Monirsadat Mirzade ${ }^{9}$, Najmeh Aletaha ${ }^{7, *}$

1. Assistant Professor of Gastroenterology, Imam Khomeini Hospital Complex, Tehran University of Medical Sciences, Tehran, Iran

2. Professor of Gastroenterology, Imam Khomeini Hospital Complex, Tehran University of Medical Sciences, Tehran, Iran

3. Internal Medicine Resident, Internal Medicine Department, Imam Khomeini Hospital Complex, Tehran University of Medical Sciences, Tehran, Iran

4. Researcher, Iran University of Medical Sciences, Tehran, Iran

5. Pathologist, Associate Professor of Tehran University of Medical Sciences, Tehran, Iran

6. Assistant Professor of Gastroenterology, Isfahan University of Medical Sciences, Isfahan, Iran

7. Associate Professor of Gastroenterology, Tehran University of Medical Sciences, Tehran, Iran

8. Assistant Professor of Gastroenterology, Ilam University of Medical Sciences, Ilam, Iran

9. Resident of Community Medicine, Bushehr University of Medical Sciences, Bushehr, Iran

* Corresponding Author:

Najmeh Aletaha,MD

Gastroentrology and Hepatology Ward, Imam Khomeini Hospital, Tehran university of Medical Science, Tehran, Iran

Tel: + 982188799446

Fax: + 982188799840

Email: dr.aletaha@gmail.com

Received: 21 Jan. 2021

Accepted: 11 Jun. 2021

\section{ABSTRACT}

\section{BACKGROUND}

Infiltration of IgG4 positive plasma cells has been detected in the colonic mucosa of patients with ulcerative colitis (UC). The aim of the study was to investigate the association between colonic mucosal infiltration of IgG4 plasma cells and the presence, activity, extension, and duration of UC.

\section{METHODS}

In this case-control study (2009-2014), 102 subjects (84 with UC/18 controls) were enrolled. Clinical records and rectosigmoid biopsies of UC patients were selected, and biopsies were stained with IgG4 monoclonal antibodies. IgG4 positive plasma cells were counted by a single pathologist.

\section{RESULTS}

Amongst 84 patients with UC, $73.8 \%$ had UC without primary sclerosing cholangitis (PSC), and 26.2\% had UC with PSC. IgG4 plasma cells were seen in 35 (41.7\%) patients with UC and $0 \%$ of controls $(p=0.001)$. The mean amount of IgG4 containing plasma cells was significantly different between active and inactive patients with UC, although it was not significantly different between UC patients with and without PSC. The presence of IgG4 infiltration was significantly associated with the extension and duration of the disease. Furthermore, IgG4 count had a sensitivity/specificity of $78.6 \% / 83.3 \%$ for the diagnosis of UC.

\section{CONCLUSION}

Our study revealed the diagnostic role of IgG4 plasma cells in the colonic mucosa of patients with UC and its association with activity, extension, and duration of disease.

\section{KEYWORDS:}

Ulcerative colitis, IgG4 plasma cells, Duration of disease, Disease activity, Extension of disease, Primary sclerosing cholangitis

Please cite this paper as:

Alborzi F, Ebrahimi Daryani N, Deihim T, Azizi Z, Azmoudeh Ardalan F, Teimouri A,Taslimi R, Roshan N,Mami M, Mirzade M, Aletaha N. Colonic Mucosal Infiltration of IgG4 Plasma Cells and Ulcerative Colitis: Determinant of Presence, Activity, Extension, and Duration of Disease. Middle East J Dig Dis 2021;13:287-293. doi: 10.34172/mejdd.2021.237 


\section{INTRODUCTION}

Ulcerative colitis (UC) is an inflammatory bowel disease (IBD) with a prevalence rate of 63.6 per 100,000 subjects. ${ }^{1}$ The incidence rate is also 6 per 100,000 people per year, with some geographical differences ranging from 1.4 million in the United States to 2.2 million in Europe., The pathogenesis includes interaction between genetic susceptibility, environmental factors, and intestinal microflora, which activate an abnormal and excessive immune response, epithelial barrier dysfunction, and eventually gastrointestinal tract inflammation, and tissue damage. UC may affect many organs other than the intestine. Extraintestinal manifestations, are reported in 21-47\% of patients with IBD. ${ }^{4}$ Autoimmune pancreatitis (AIP) is a pancreatic manifestation of a systemic disorder called IgG4-related systemic disease. This disorder is characterized by elevated serum levels of IgG4 and sclerosing lymphoplasmacytic inflammation reaction in one or more organs. ${ }^{5,6}$ Previous studies have shown a promising correlation between autoimmune pancreatitis and IBD. Studies have shown patients with IgG4 related disease and colitis have an aggressive clinical course and resistance to traditional treatment. ${ }^{7,8}$ The extent and severity of IBD may be increased in patients with concomitant IBD and AIP. The IgG4 positive plasma cells on colonic biopsies may imply that IBD is an extrapancreatic feature of AIP. ${ }^{9,10}$ The main extracolonic manifestation of UC is primary sclerosing cholangitis (PSC). It is assumed that immunologically-mediated bile duct destruction is a major mechanism for developing PSC. However, the antigen that is responsible for immune response and the mechanism by which autoantibodies or abnormally activated $\mathrm{T}$ cells lead to the clinical presentation of the disease is unknown, ${ }^{11-13}$ In a subgroup of UC patients with PSC, the serum IgG4 level has been shown to be elevated, and the clinical course of these patients varies compared with IgG4 negative patients with PSC. ${ }^{14,15}$ The role of IgG4 containing plasma cells in the pathophysiology of patients with IBD, despite these findings, is unclear, and the relationship between the presence of these plasma cells and the activity of IBD or concurrent PSC is a matter of debate. In this study, we evaluated the colonic biopsies of patients with UC to assess the association between colonic mucosal infiltration of IgG4 secreting plasma cells with the presence, activity, extension, and duration of ulcerative colitis

\section{MATERIALS AND METHODS}

\section{Patients}

In this case-control study, 102 consecutive subjects, including 62 cases with merely UC (42 active and 20 inactive), 22 patients with concomitant UC and PSC (11 active, 11 inactive), and 18 controls were enrolled. All patients and controls were chosen from those with pathological biopsy samples who had undergone colonoscopy and biopsy in Imam Khomeini Hospital, Tehran, Iran, from April 2009 to September 2014. This study was approved by the Institutional Ethics Committee of Tehran University of Medical Sciences (TUMS). Biological materials (biopsy specimens) were provided by the Iran National Tumor Bank, which is funded by the Cancer Institute of TUMS, for cancer research. All patients with UC were diagnosed by clinical, pathological, and endoscopic findings using the Mayo Scoring System for Assessment of Ulcerative Colitis Activity. Patients with a history of malignancy and allergic diseases were excluded. The diagnosis of PSC was documented based on laboratory, biopsy, and imaging (magnetic resonance cholangiopancreatography, MRCP) findings. The control group did not have a history of IBD, inflammatory, malignant, or allergic diseases. All of the 18 controls had normal colonoscopy and biopsy. The activity of colitis was defined based on histological findings. ${ }^{16,17}$ Patients' age, sex, type of IBD, endoscopic severity, disease activity, duration and extent of disease, and endoscopic findings were obtained retrospectively from medical records.

\section{Immunohistochemistry}

Formalin-fixed and paraffin-embedded sections were obtained then tissue sections were stained with monoclonal IgG4 antibody (IgG4 Invitrogen, code: MG1042). A single pathologist who was blinded to the previous diagnosis reviewed the number of IgG4 positive plasma cells. IgG4 was considered positive if more than $10 \mathrm{IgG} 4$ plasma cells in each high power field (HPF) were present (figures $1 \& 2$ ). 


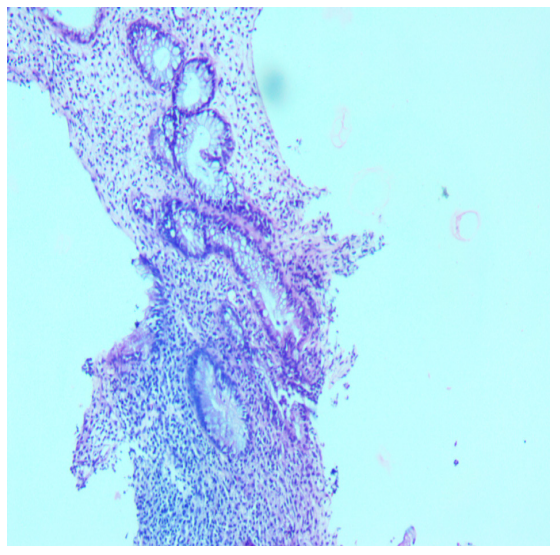

Fig. 1: The photomicrograph shows large intestinal mucosa with distorted crypt architecture accompanied by moderate lymphoplasmacytic infiltration in lamina propria. $H \& E$ 40x

\section{Statistical analysis}

All statistical analyses were performed using SPSS software (version 18). Descriptive statistics were reported as mean \pm standard deviation (minimum-maximum) for quantitative variables and frequency (percentage) for qualitative variables. Bivariate correlation for categorical data was determined using Fisher's exact test and for continuous data Mann-Whitney U test. Receiver operating characteristic analysis determined the cutoff point and sensitivity and specificity of IgG4 for diagnosis of UC from the control group, determining disease activity and predicting the time of IgG4 positivity in patients with UC. All $p$ values $<$ 0.05 were considered statistically significant.

\section{RESULTS}

\section{Demographic Data}

A total of 102 cases (84 [82.4\%] UC patients and 18 $(17.6 \%)$ controls) were enrolled in our study. Among 84 patients with UC, 62 (73.8\%) had UC without PSC (42 [67.7\%] active \& 20 [32.3\%] inactive) and 22 (26.2\%) patients had UC with PSC (11 [50\%] active and 11 [50\%] inactive). Demographic and clinical data are shown in table 1 .

The male population was predominant in both patients and control groups. The mean age of the patients with UC was $36.71 \pm 12.16$ (19-69) years, and the mean age of the control group was $45.11 \pm 15.41$ (23-83) years. Patients with PSC were slightly younger than patients without PSC (35.72 \pm 9.49 [23-52] vs. $37.06 \pm 13.02$ [19-

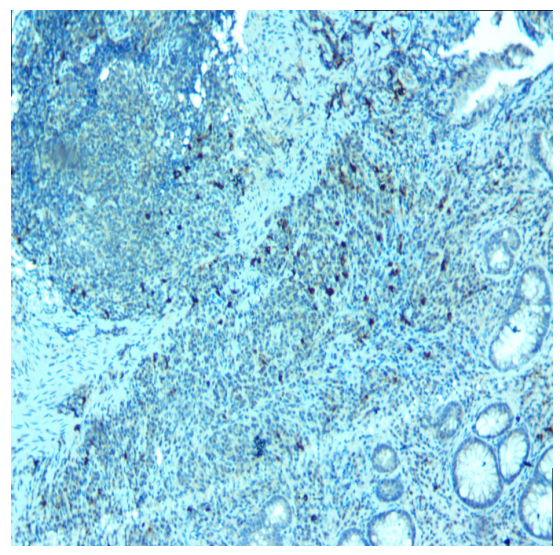

Fig. 2: The figure depicts moderate infiltration of IgG4-stained plasma cells in lamina propria. IgG4 immunostain, 40x

69] years). The mean duration of disease in patients with PSC was longer than patients without PSC $(5.63 \pm 1.81$ [2-9] vs. $3.12 \pm 2.22$ [0-10] years). Based on histological findings, among patients with active UC, 12 (28.6\%) had mild colitis, and $30(71.4 \%)$ had moderate or severe colitis. According to endoscopic findings, 24 (28.6\%) patients had pancolitis, $52(61.9 \%)$ had left-sided colitis, and in 8 $(9.5 \%)$ patients, inflammation was limited to the rectum. All patients had negative history and laboratory studies for AIP.

\section{Tissue IgG4 Immunohistochemistry}

Biopsies from patients with UC showed significant IgG4 bearing plasma cells infiltration compared with the control group, $35(41.7 \%)$ out of 84 patients versus $0(0 \%)$ in the control group (Fisher exact $p=0.001)(\mathrm{IgG} 4$ count in cases $8.55 \pm 10.57$ [0-60] vs. $0.33 \pm 0.84$ [0-3] in the controls) (figure1). The chance of having significant IgG4 infiltration in patients with UC was 1.7 times more than the control group (OR: 1.7, 95\% CI $=1.43-2.05$ ) (figure 2 ). There was also a significant correlation between disease activity and IgG4 infiltration among patients with active and inactive UC $(p=0.001)$. We did not find any relationship between disease severity and $\mathrm{IgG} 4$ infiltration among patients with mild and moderate to severe active UC $(p=0.268)$. Patients with pancolitis had significant IgG4 infiltration $(70 \%)$ compared with left-sided colitis or proctitis $(34 \%)(p=0.001)$. Nine $(40 \%)$ out of the 22 patients with UC and PSC had IgG4 count more than 10/ HPF, compared with 26 (41\%) out of 62 UC patients with- 
Table 1: Demographic and clinical data

\begin{tabular}{|c|c|c|c|c|c|}
\hline Variables & & $\mathbf{U C}$ & $\begin{array}{c}\text { UC with PSC } \\
\quad \mathrm{N}=\mathbf{2 2}\end{array}$ & $\begin{array}{c}\text { UC without PSC } \\
\quad \mathrm{N}=62\end{array}$ & $\begin{array}{c}\text { Control } \\
\mathbf{N}=\mathbf{1 8}\end{array}$ \\
\hline \multirow{2}{*}{ Sex } & Male & $47(56 \%)$ & $14(63.6 \%)$ & $33(53.2 \%)$ & $10(55.6 \%)$ \\
\hline & Female & $37(44 \%)$ & $8(36.4 \%)$ & $29(46.8 \%)$ & $8(44.4 \%)$ \\
\hline \multicolumn{2}{|l|}{ Mean age at colonoscopy } & $\begin{array}{c}36.71 \pm 12.16 \\
(19-69)\end{array}$ & $\begin{array}{c}35.72 \pm 9.49 \\
(23-52)\end{array}$ & $\begin{array}{c}37.06 \pm 13.02 \\
(19-69)\end{array}$ & $\begin{array}{l}45.11 \pm 15.41 \\
\quad(23-83)\end{array}$ \\
\hline \multicolumn{2}{|l|}{ Duration of disease } & $\begin{array}{l}3.78 \pm 2.38 \\
\quad(0-10)\end{array}$ & $\begin{array}{l}5.63 \pm 1.81 \\
\quad(2-9)\end{array}$ & $\begin{array}{l}3.12 \pm 2.22 \\
\quad(0-10)\end{array}$ & \\
\hline \multirow{2}{*}{ Disease activity } & Active & $53(63.1 \%)$ & $11(50 \%)$ & $42(67.7 \%)$ & \\
\hline & Inactive & $31(36.9 \%)$ & $11(50 \%)$ & $20(32.3 \%)$ & \\
\hline \multirow{2}{*}{$\begin{array}{l}\text { Degree of inflam- } \\
\text { mation }\end{array}$} & Mild & $12(28.6 \%)$ & $1(100 \%)$ & $11(26.8 \%)$ & \\
\hline & $\begin{array}{l}\text { Moderate to } \\
\text { severe }\end{array}$ & $30(71.4 \%)$ & $0(0 \%)$ & $30(73.2 \%)$ & \\
\hline \multirow{3}{*}{$\begin{array}{l}\text { Extension of } \\
\text { disease }\end{array}$} & Proctitis & $8(9.5 \%)$ & $1(4.5 \%)$ & $7(11.3 \%)$ & \\
\hline & Left colitis & $52(61.9 \%)$ & $13(59.1 \%)$ & $39(62.9 \%)$ & \\
\hline & Pancolitis & $24(28.6 \%)$ & $8(36.4 \%)$ & $16(25.8 \%)$ & \\
\hline \multirow{3}{*}{$\begin{array}{l}\text { Mean IgG4 count } \\
\text { Mean } \pm \mathrm{SD} \text { (range) }\end{array}$} & Total mean & $\begin{array}{c}8.55 \pm 10.57 \\
(0-60)\end{array}$ & $\begin{array}{l}7.54 \pm 9.42 \\
\quad(0-40)\end{array}$ & $\begin{array}{l}8.91 \pm 10.99 \\
\quad(0-60)\end{array}$ & $\begin{array}{l}0.33 \pm 0.84 \\
\quad(0-3)\end{array}$ \\
\hline & Active UC & $\begin{array}{c}12.86 \pm 11.17 \\
(0-60)\end{array}$ & $\begin{array}{l}14.09 \pm 9.55 \\
\quad(1-40)\end{array}$ & $\begin{array}{l}12.54 \pm 11.64 \\
(0-60)\end{array}$ & \\
\hline & Inactive UC & $\begin{array}{c}1.19 \pm 1.95 \\
(0-10)\end{array}$ & $\begin{array}{c}1.0 \pm 1 \\
(0-3)\end{array}$ & $\begin{array}{l}1.3 \pm 2.34 \\
(0-10)\end{array}$ & \\
\hline
\end{tabular}

*Results are reported as mean \pm standard deviation (minimum-maximum) for quantitative variables and frequency (percentage) for qualitative variables. $* *$ UC: Ulcerative colitis, PSC: Primary sclerosing cholangitis

A

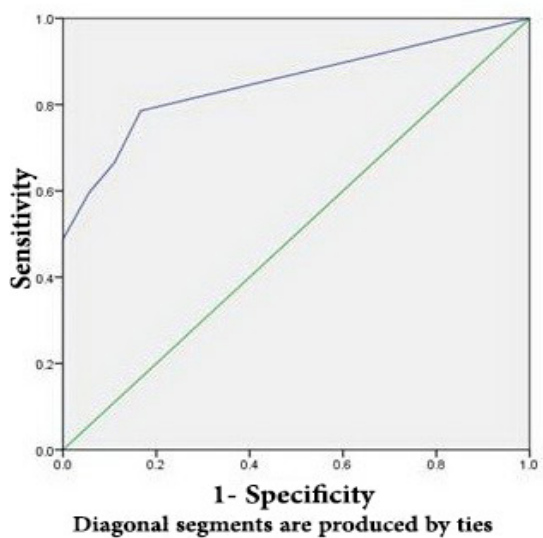

B

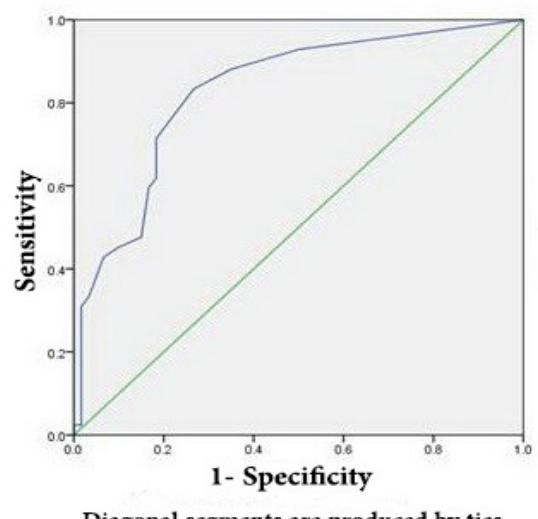

Diagonal segments are produced by ties
C

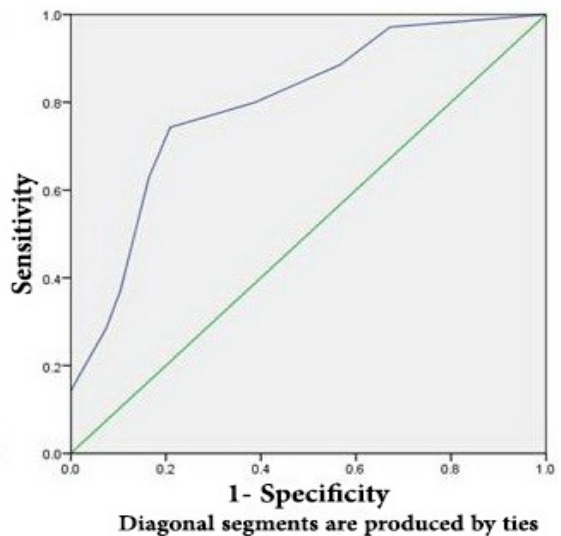

Fig. 3: A: ROC curve for determining the accuracy of IgG4 count in the diagnosis of patients with ulcerative colitis from the control, B: ROC curve for assessing the accuracy of IgG4 count in determining disease activity, C: ROC curve for predicting IgG4 positivity during the disease course

out PSC, although the difference was not statistically significant ( $p=0.9331)$. There was a significant correlation between the duration and extension of disease and IgG4 plasma cell infiltration $(p=0.001)$. The mean IgG4 count was higher in the active PSC_UC group (14.09 \pm 9.55 [140]) than in other groups. The mean count of $\mathrm{IgG} 4$ was $12.54 \pm 11.64[0-60]$ in active UC-non PSC group, $1.3 \pm$
$2.34(0-10)$ in the inactive UC-non PSC group, $1.0 \pm 1(0-$ 3 ) in inactive UC-PSC, and $0.33 \pm 0.84(0-3)$ in the controls. The mean number of IgG4 laden plasma cells was higher in the active UC and PSC group compared with inactive UC patients. This was statistically significant $(p=0.001)$.

Receiver operating characteristic analysis

On receiver operating characteristic analysis $\mathrm{IgG} 4$ 
count had sensitivity and specificity of $78.6 \%$ and $83.3 \%$, respectively, in cutoff point of 0.5 with an area under curve of $0.85,95 \% \mathrm{CI}(0.77-0.92)$, and $p$ value $<0.001$ for diagnosis of UC from the control group (figure3). Also, it had sensitivity and specificity of $84.9 \%$ and $87.8 \%$ in cutoff point of 2.5 with an area under the curve of $0.92,95 \% \mathrm{CI}=0.87-0.97$, and $p<0.001$ for determining disease activity (figure 3 ). Duration of disease had a sensitivity of $74.3 \%$ with a specificity of $80 \%$ with a cutoff point of 3.5 years for predicting positivity of IgG4 (area under curve $=0.796,95 \% \mathrm{CI}=0.70-0.88$, and $p<0.001$ ) (figure3).

\section{DISCUSSION}

The aim of this retrospective study was to assess the colonic mucosal infiltration of IgG4 plasma cells and the presence, extension, and activity of UC. Our study showed that patients with $\mathrm{UC}$ had a significantly higher proportion of IgG4 infiltration vs. the control group. Previous studies have shown IgG4 infiltration in patients with autoimmune pancreatitis and claim that patients with AIP had IBD mimicking colitis; however, our subjects did not have any signs and symptoms of AIP. ${ }^{18}$ The immune system has a particular role in the pathogenesis of IBD. T-helper1 response and its cytokines like IL2, TNF $\alpha$, and interferon $\gamma$ are predominant in Crohn's disease. In contrast, T-helper 2 response with an increase in IL4, IL5, and IL10 is the major response seen in UC..$^{18,19}$ These cytokines also have a significant role in the eosinophilia, elevated serum IgG4 and IgE concentrations, and progression of fibrosis that are characteristic of IgG4-related disease. , $, 6,20^{2}$ It was postulated that the role of IgG4 infiltration in the colonic mucosa of patients with $\mathrm{UC}$ is due to concomitant AIP, but it seems that IgG4 colonic infiltration is not relevant to AIP. In our study and some similar studies, none of the UC patients who had IgG4 infiltration in their colonic mucosa had evidence of AIP. Although, our study and few other studies have shown significant concentration of IgG4 plasma cells in colonic mucosa of patients with UC, the specific role of this antibody is yet to be determined.

Moreover, our study showed that IgG4 plasma cell infiltration was correlated with duration, extension, and activity of UC, but not with the degree of inflammation. Our findings were consistent with a study done by Raina and colleagues. Moreover, Hartman and co-workers reported refractory IBD disease in those with higher IgG4 cells infiltration. ${ }^{21}$ A probable explanation for this association is the leaky gut hypothesis. The gut of the gastrointestinal tract is exposed to different food antigens and bacteria. It seems that food allergens, gut microbiota, and gut immune response can change by different food consumption. Delayed reactions to food are predominately IgG reactions. ${ }^{22}$ Among four kinds of $\operatorname{IgG}, \operatorname{IgG} 1$, and IgG4 are increased in allergic reactions, while $\mathrm{IgG} 4$ is found in the gut. $\mathrm{IgG} 4$ has blocking action in repeated food antigen exposures and IgE production. It acts to decrease the IgE-allergen complex..$^{23,24}$ On the other hand, the long-term IgG4 stimulation can lead to leaky gut or increase gut permeability and prolong enterocyte damage and chronic inflammation. This allows antigens and bacteria to cross the intestinal epithelium and enter the circulation and activate the immune system. ${ }^{25,26}$ Our study shows that $\mathrm{IgG} 4$ plasma cell is more abundant in active UC and is rarely observed in the inactive form; therefore the role of food allergy and its related chronic inflammation should be considered in the pathogenesis of active $\mathrm{UC}$ with regards to the presence of IgG4. In our study, those with pancolitis had significantly higher IgG4 infiltration compared with those with left colitis or proctitis, which was consistent with the findings of Virk and colleagues.

The mean amount of IgG4 plasma cells varied between previous studies from 7\% in Alghamdi ${ }^{27}$ study to $38 \%$ in Virk study 18 and $41 \%$ in ours. This difference could be partially explained by different environmental risk factors such as diet, microbiota, and geographic variations in different study populations. While the result of our study showed a sensitivity and specificity of $84.9 \%$ and $87.8 \%$ in cutoff point of 2.5 for determining disease activity, Raina and colleagues did not find any correlation between the number of IgG4 and degree of disease activity in differentiating the UC patients with the controls. In addition, we found that patients with more than 3.5 years of disease duration had more possibility of having IgG4 positive results than others with sensitivity and specificity of $74.3 \%$ and $80 \%$, respectively.

It has been shown that serum IgG4 level is elevated in about $10 \%$ of patients with PSC. These groups of patients have distinct clinical courses and corticosteroid responses. 
There is no documented data showing the presence of IgG4 plasma cells on their colonic mucosal biopsies. In our study, $40 \%$ of patients with PSC had significant mucosal infiltration, but their clinical course and treatment response were not available to determine whether these patients are also good corticosteroid responders or not. Furthermore, passing bacteria through the inflamed and damaged barrier of the gut to the circulation is a possible mechanism for developing PSC. ${ }^{13}$ This mechanism is similar to IgG4 related chronic inflammation due to food allergens and gut microbiota, which may predispose patients with UC to PSC.

Although we carried out a strong study, it did come with its limitations. Firstly, this was a case-control study, and we did not have any information about the clinical course of the patients' disease. We did not enroll patients with Crohn's disease; therefore the pathophysiologic role of IgG4 and the differences in both diseases were not achieved. We did not measure patients' serum IgG4 level, so the association of tissue IgG4 infiltration with serum IgG4 was not possible in our study. Lastly, we were not aware of patients' medications during colonoscopy and biopsy; while corticosteroid and anti-TNF drugs can influence the degree of inflammation, so the effect of these drugs on tissue IgG4 was not evident in our study.

In conclusion, our study revealed that a portion of active UC cases, whether accompanying with PSC or not had significant infiltration of IgG4 plasma cells in their colonic mucosa. All of these results from our study can bring this hypothesis that IgG4 could be a factor for determining disease activity, confirmation of diagnosis, and duration of disease. Also, our findings suggest an allergic IgG4 related pathway in addition to B cell-mediated mechanism for activity of UC. Further studies are needed to confirm this hypothesis and determine the real role of tissue IgG4 in patients with IBD.

\section{ACKNOWLEGMENTS:}

We thank Tehran University of Medical Sciences and the Cancer Institute of Tehran University of Medical Sciences for the financial support of our study.

\section{ETHICAL APPROVAL}

There is nothing to be declared.

\section{CONFLICT OF INTEREST}

The authors declare no conflict of interest related to this work.

\section{REFERENCES}

1. Asakura K, Nishiwaki Y, Inoue N, Hibi T, Watanabe M, Takebayashi T. Prevalence of ulcerative colitis and Crohn's disease in Japan. J Gastroenterol 2009;44:65965. doi:10.1007/s00535-009-0057-3

2. Sood A, Midha V, Sood N, Bhatia A, Avasthi G. Incidence and prevalence of ulcerative colitis in Punjab, North India. Gut 2003;52:1587-90. doi:10.1136/gut.52.11.1587

3. Loftus Jr EV. Clinical epidemiology of inflammatory bowel disease: incidence, prevalence, and environmental influences. Gastroenterology 2004;126:1504-17. doi:10.1053/j.gastro.2004.01.063

4. Ramos LR, Sachar DB, DiMaio CJ, Colombel J-F, Torres J. Inflammatory bowel disease and pancreatitis: a review. $J$ Crohns Colitis 2015;10:95-104. doi:10.1093/ecco-jcc/jjv153

5. Stone JH, Zen Y, Deshpande V. IgG4-related disease. IgG4-related disease. $N$ Engl J Med 2012;366:539-51. doi:10.1056/NEJMra1104650

6. Deshpande V, Zen Y, Chan JK, Eunhee EY, Sato Y, Yoshino T, et al. Consensus statement on the pathology of IgG4-related disease. Mod Pathol 2012;25:1181. doi:10.1038/modpathol.2012.72.

7. Zhang L, Chari S, Smyrk TC, Deshpande V, Klöppel G, Kojima M, et al. Autoimmune pancreatitis (AIP) type 1 and type 2: an international consensus study on histopathologic diagnostic criteria. Pancreas 2011;40:1172-9. doi:10.1097/MPA.0b013e318233bec5

8. Shimosegawa T, Chari ST, Frulloni L, Kamisawa T, Kawa $\mathrm{S}$, Mino-Kenudson $\mathrm{M}$, et al. International consensus diagnostic criteria for autoimmune pancreatitis: guidelines of the International Association of Pancreatology. Pancreas 2011;40:352-8. doi:10.1097/MPA.0b013e3182142fd2

9. Kamisawa T, Chari ST, Giday SA, Kim M-H, Chung JB, Lee KT, et al. Clinical profile of autoimmune pancreatitis and its histological subtypes: an international multicenter survey. Pancreas 2011;40:809-14. doi:10.1097/ MPA.0b013e3182258a15

10. Ravi K, Chari ST, Vege SS, Sandborn WJ, Smyrk TC, Loftus Jr EV. Inflammatory bowel disease in the setting of autoimmune pancreatitis. Inflamm Bowel Dis 2009;15;1326-30. doi:10.1002/ibd.20898

11. Lee Y-M, Kaplan MM. Primary sclerosing cholangitis. N Engl J Med 1995;332:924-33. doi:10.1056/ NEJM199504063321406

12. Fausa O, Schrumpf E, Elgjo K, editors. Relationship of inflammatory bowel disease and primary sclerosing cholangitis. Semin Liver Dis 1991;11:31-9. doi: 10.1055/s- 
2008-1040420

13. Palmer K, Duerden B, Holdsworth C. Bacteriological and endotoxin studies in cases of ulcerative colitis submitted to surgery. Gut 1980;21:851-4. doi:10.1136/gut.21.10.851

14. Mendes FD, Jorgensen R, Keach J, Katzmann JA, Smyrk $\mathrm{T}$, Donlinger J, et al. Elevated serum IgG4 concentration in patients with primary sclerosing cholangitis. Am $J$ Gastroenterol 2006;101:2070-5. doi:10.1111/j.15720241.2006.00772.x

15. Hirano K, Kawabe T, Yamamoto N, Nakai Y, Sasahira N, Tsujino T, et al. Serum IgG4 concentrations in pancreatic and biliary diseases. Clin Chim Acta 2006;367:181-4. doi:10.1016/j.cca.2005.11.031

16. Hefti MM, Chessin DB, Harpaz N, Steinhagen RM, Ullman TA. Severity of inflammation as a predictor of colectomy in patients with chronic ulcerative colitis. Dis Colon Rectum 2009;52:193-7. doi:10.1007/DCR.0b013e31819ad456

17. DeRoche TC, Xiao S-Y, Liu X. Histological evaluation in ulcerative colitis. Gastroenterol Rep (Oxf) 2014;2:178-92. doi: 10.1093/gastro/gou031

18. Virk R, Shinagare S, Lauwers GY, Yajnik V, Stone JH, Deshpande V. Tissue IgG4-positive plasma cells in inflammatory bowel disease: a study of 88 treatment-naive biopsies of inflammatory bowel disease. Mod Pathol 2014;27:454. doi:10.1038/modpathol.2013.121

19. Boden EK, Snapper SB. Regulatory T cells in inflammatory bowel disease. Curr Opin Gastroenterol 2008;24:73341. doi:10.1097/MOG.0b013e328311f26e

20. Pieringer H, Parzer I, Wöhrer A, Reis P, Oppl B, Zwerina J. IgG4-related disease: an orphan disease with many faces. Orphanet J Rare Dis 2014;9:110. doi:10.1186/s13023014-0110-z

21. Hartman DJ, Binion DG. Tu1268 Distribution of IgG4 Cells in Medically Refractory Patients With Inflammatory Bowel Disease. Gastroenterology 2012;142:S-789. doi: 10.1016/S0016-5085(12)63062-5

22. Jyonouchi H. Non-IgE mediated food allergy. Inflamm Allergy Drug Targets 2008;7:173-80. doi:10.2174/187152808785748119

23. Bullock R, Barnett D, Howden M. Immunologic and clinical responses to parenteral immunotherapy in peanut anaphylaxis-a study using IgE and IgG4 immunoblot monitoring. Allergol Immunopathol (Madr) 2005;33:250-6. doi: $10.1157 / 13080927$

24. Paganelli R, Pallone F, Montano S, Le Moli S, Matricardi $\mathrm{P}$, Fais $\mathrm{S}$, et al. Isotypic analysis of antibody response to a food antigen in inflammatory bowel disease. Int Arch Allergy Appl Immunol 1985;78:81-5. doi: 10.1159/000233867

25. Kemeny DM, Urbanek R, Amlot PL, Ciclitira PJ, Richards D, Lessof MH. Sub-class of IgG in allergic disease I. IgG sub-class antibodies in immediate and nonimmediate food allergy. Clin Allergy 1986;16:571-81. doi:10.1111/j.1365-2222.1986.tb01996.x

26. Paganelli R, Fagiolo U, Cancian M, Scala E. Intestinal permeability in patients with chronic urticaria-angioedema with and without arthralgia. Ann Allergy 1991;66:181-4.

27. Alghamdi S, Barkin J, Trotter M, Sorrentino D, Martinez AE. IgG4-positive Plasma Cell Infiltration in the Setting of Ulcerative Colitis. J Gastroenterol Hepatol Res 2012;1:320-2.doi: 10.6051/j.issn.2224-3992.2012.01.157 